\title{
Novel insights into human intestinal epithelial cell proliferation in health and disease using confocal microscopy
}

\author{
T C Savidge, J A Walker-Smith, A D Phillips
}

Academic Department of Paediatric

Gastroenterology,

Queen Elizabeth

Hospital for Children,

Hackney, London

T C Savidge

J A Walker-Smith

A D Phillips

Laboratory of

Intestinal Biology,

Department of

Cellular Physiology,

The Babraham

Institute, Babraham,

Cambridge

T C Savidge

Correspondence to:

Dr T C Savidge, Laboratory

of Intestinal Biology,

Department of Cellular

Physiology, The Babraham

Inysiology, The Babrate, Babraham

Institute, Babraham,

Accepted for publication

15 July 1994

\begin{abstract}
Measurement of intestinal epithelial cell proliferation has provided important information concerning tissue responses in neoplasia, enteropathy, and adaptation. This study reexamined current concepts regarding intestinal proliferation by using a novel confocal microscopical technique to map mitotic figures accurately within the intact three dimensional framework of the crypts of Lieberkiuhn. The ability of confocal microscopy to simultaneously measure crypt morphology and internal detail, without disrupting spatial cell arrangements, has provided important new data. These question the ability of existing methods to accurately measure and interpret proliferative changes in the gut. This work investigates intestinal proliferation in children with coeliac disease, a well defined hyperproliferative disorder, in comparison with the healthy intestine. These results show that crypt cell division occurs with an equal probability in health and disease. In addition, increased crypt cell production rates are largely caused by a change in crypt size rather than a change in cell cycle time or crypt growth fraction and, as such, alter our understanding of kinetic responses in gastrointestinal disease.
\end{abstract}

(Gut 1995; 36: 369-374)

Keywords: confocal microscopy, intestinal epithelial cell proliferation, coeliac disease.
Figure 1: Haematoxylin and eosin stained histological section of $(A)$ histologically normal intestinal mucosa and $(B)$ coeliac mucosa (original magnification $\times 65$ ).
The high degree of structural and kinetic organisation that is characteristic of the intestine is a powerful argument for its use as a model for epithelial cell proliferation in health and disease. ${ }^{1-14}$ Many of these investigations have relied on the use of metaphase arrest agents or nucleotide analogues, or both to provide detailed calculations of crypt stem cell populations, epithelial birth rates, and growth fractions. In humans, especially in children, the widespread use of such agents is ethically unacceptable and quantitative measurements of intestinal proliferation have been largely restricted to counting mitotic figures either in longitudinal sections or in Feulgen stained crypt squashes. ${ }^{15}$ It has long been realised, however, that the accuracy of these techniques is severely hampered by having to count crypt cells in two and three dimensions (D), respectively. ${ }^{16}$ This is compounded further as nuclei entering mitosis migrate centripetally towards the lumen of the crypt. Several attempts have been made to correct for such geometrical considerations, for example, Tannock's correction factor, an important assumption being that crypts are cylindrical. ${ }^{17}$

This study describes a novel confocal microscopical technique used to investigate small intestinal epithelial cell proliferation in children. By means of non-invasive optical sectioning through microdissected crypts we have obtained high resolution 3-D data enabling mitotic figures to be mapped accurately relative to the architecture of individual intact crypts. Histologically normal crypts were compared with those from children with active coeliac disease, where severe crypt hyperplastic flat mucosa is seen. The well defined hyperproliferative state recorded in this disease allowed us to critically re-examine adaptive intestinal proliferative responses ${ }^{18}$ to gut damage using confocal microscopical and longitudinal section methods, respectively.

\section{Methods}

\section{Patients}

Samples of jejunal mucosa were obtained from children with chronic diarrhoea or a failure to thrive, or both. Tissue was collected from children undergoing routine investigative small intestinal biopsies by mouth with fully informed consent. Specimens harvested using a paediatric Crosby capsule, were classified as controls (confocal microscopical studies 6F:5M, median age 31 months; longitudinal section studies $5 \mathrm{~F}: 6 \mathrm{M}$ median age 33 months) - that is, histologically normal tissue from 
Kinetic crypt data

\begin{tabular}{|c|c|c|c|c|c|c|c|c|}
\hline & $\begin{array}{l}\text { Crypt } \\
\text { length } \\
\text { (cells) }\end{array}$ & $\begin{array}{l}\text { Crypt } \\
\text { circumference } \\
\text { (cells) }\end{array}$ & $\begin{array}{l}\text { Crypt cell } \\
\text { population } \\
\text { (cells) }\end{array}$ & $\begin{array}{l}\text { Growth } \\
\text { fraction } \\
\left(I_{\mathrm{p}}\right)\end{array}$ & $\begin{array}{l}\text { Proliferation } \\
\text { compartment } \\
\text { (cells) }\end{array}$ & $\begin{array}{l}\text { Maturation } \\
\text { compartment } \\
\text { (cells) }\end{array}$ & $\begin{array}{l}\text { CCPR } \\
\text { (cells/crypt/h) }\end{array}$ & $\begin{array}{l}\text { Corrected } \\
M I \\
(\%)\end{array}$ \\
\hline $\begin{array}{l}\text { Controls } \\
\text { CM } \\
\text { LS }\end{array}$ & $\begin{array}{l}33(2) \\
33(2) \ddagger\end{array}$ & $\begin{array}{l}20(0.5) \\
22(0 \cdot 7) \ddagger\end{array}$ & $\begin{array}{l}649(13) \\
740(14)^{\star}\end{array}$ & $\begin{array}{l}0 \cdot 82 \\
0 \cdot 70\end{array}$ & $\begin{array}{l}532 \\
518\end{array}$ & $\begin{array}{l}117 \\
222\end{array}$ & $\begin{array}{c}5 \cdot 6(0 \cdot 2) \\
14 \cdot 6(0 \cdot 8) \dagger\end{array}$ & $\begin{array}{l}1.01(0.04) \\
2.97(0.22) \dagger\end{array}$ \\
\hline $\begin{array}{l}\text { CM } \\
\text { LS }\end{array}$ & $\begin{array}{l}74(3) \\
71(4) \ddagger\end{array}$ & $\begin{array}{l}35(1 \cdot 0) \\
35(1 \cdot 3) \ddagger\end{array}$ & $\begin{array}{l}2332(120) \\
2477(60) \ddagger\end{array}$ & $\begin{array}{l}0.84 \\
0.60\end{array}$ & $\begin{array}{l}1959 \\
1486\end{array}$ & $\begin{array}{r}373 \\
1265\end{array}$ & $\begin{array}{l}22 \cdot 1(2 \cdot 2) \\
55 \cdot 4(4 \cdot 6) \dagger\end{array}$ & $\begin{array}{l}1.13(0.07) \\
4.21(0.41) \dagger\end{array}$ \\
\hline
\end{tabular}

Mean (SEM) crypt values measured using either confocal microscopy (CM) or longitudinal sections (LS) from control and coeliac disease intestinal mucosa are compared statistically ( ${ }^{\prime}, t ; p<0.05$ and 0.001 , respectively; $\ddagger=N S$ ). The growth fraction

$\left(I_{p}\right)$ is calculated from a knowledge of $I_{m} \max _{50 \%}$, utilising a curve fitting program on Genstat 5 computer software to calculate $I_{m}$ $\left(I_{p}\right)$ is calculated from a knowledge of $I_{m} \max _{50 \%}$, utilising a curve fitting program on Genstat 5 computer software to calculate $I_{m}$

children where a gastrointestinal cause for their symptoms had been excluded, or as coeliac disease (confocal microscopical studies; 4F:2M, median age 33 months; longitudinal section studies $6 \mathrm{~F}: 6 \mathrm{M}$, median age 37 months) - that is, severe crypt hyperplastic flat mucosa in a child who responded clinically and histologically to gluten exclusion or in a child receiving a gluten challenge after the finding of a normal mucosa while receiving a gluten free diet. ${ }^{19}$
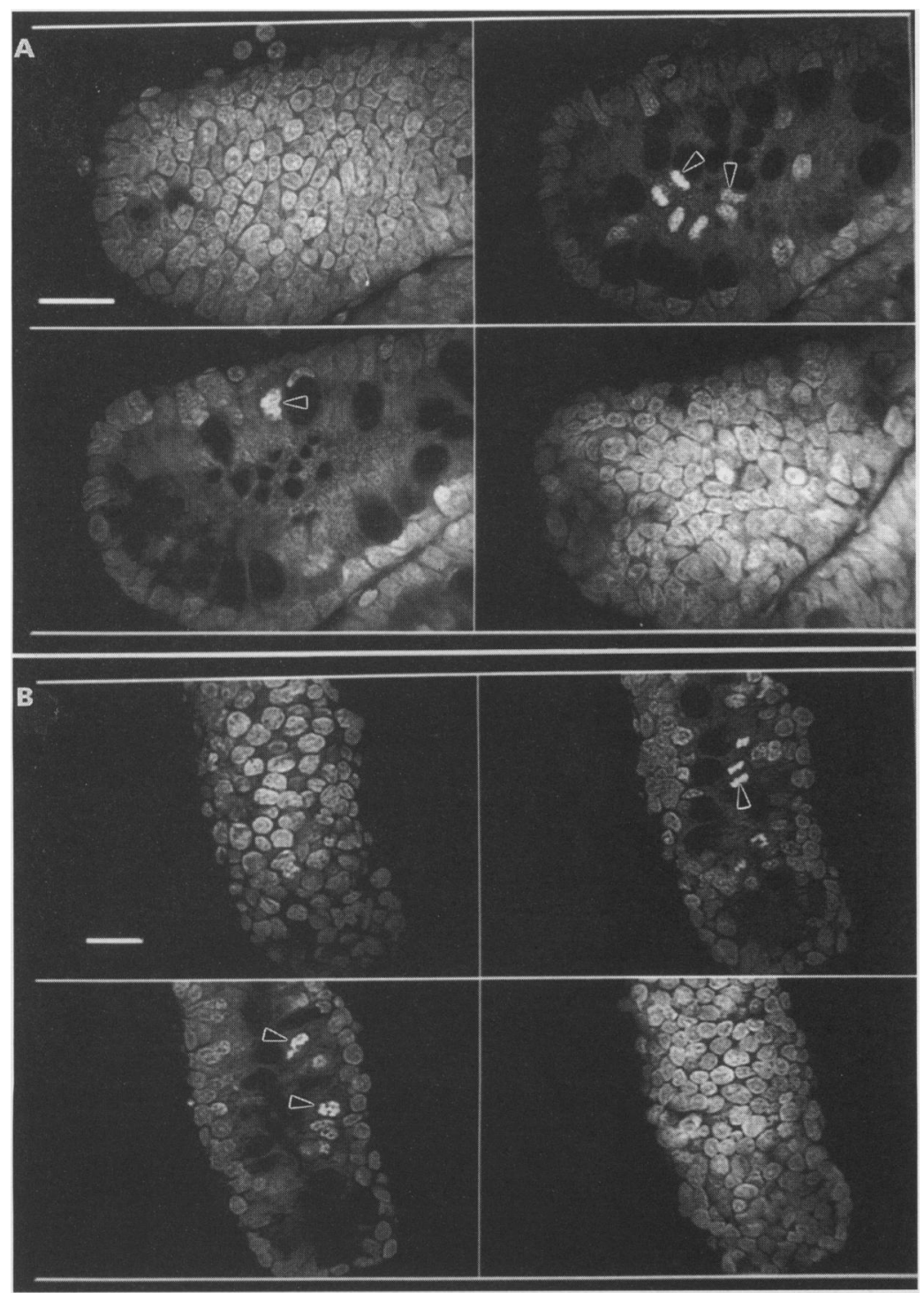

Figure 2: Confocal imaging of propidium iodide stained small intestinal crypts from children. (A) Histologically normal crypt (10 $\mu \mathrm{m}$ increments; scale bar represents $20 \mu \mathrm{m})$ (B) lower half of coeliac crypt (15 $\mu \mathrm{m}$ increments; scale bar represents $20 \mu \mathrm{m})$. Arrowheads indicate individual mitoses within the crypts.
Processing mucosal biopsy specimens for confocal microscopy

Samples of mucosa were fixed in $10 \%$ phosphate buffered formol saline $(\mathrm{pH} 7 \cdot 4)$ at $4^{\circ} \mathrm{C}$ for 48 hours. Tissue was then incubated with $2 \%$ Triton-X (Sigma, Poole, Dorset) for 30 minutes at room temperature, followed by a 30 minute incubation with $50 \mu \mathrm{M}$ ammonium chloride at room temperature. Tissue was finally stained with $10 \mu \mathrm{g}$ propidium iodide $/ \mathrm{ml}$ phosphate buffered saline (Cambridge BioScience, Cambridge) for 10 minutes at room temperature, with agitation on a titertek shaker set at $80 \%$ maximum speed (Model DSGTitertek, Flow Laboratories, High Wycombe). Intestinal tissues were carefully microdissected and individual crypts still attached to a villus base were mounted in phosphate buffered saline:glycerol (1:1).

\section{Confocal microscopy of intestinal crypts}

Fluorescently labelled mitotic and non-dividing nuclei in microdissected crypts were analysed using a Bio-Rad MRC 500/600 confocal microscope, attached to a Nikon Optiphot microscope, at a $514 \mathrm{~nm}$ excitation wavelength (Bio-Rad, Hemel Hempstead). Serial confocal images were routinely taken at $2.5 \mu \mathrm{m}$ optical increments $( \pm 0.5 \mu \mathrm{m}$ lateral resolution; Nikon $\times 40$ oil immersion objective) through the crypts thereby ensuring that no nuclei were omitted from the study. Serial confocal images were subsequently stored on a 650 Megabyte Sony Optical Disc (Inmac, London) for image analysis of serial optical sections. The number and position of individual crypt cell nuclei was recorded on a colour television monitor. This permitted an accurate enumeration of the total crypt cell population and also the mapping of mitotic figures within single crypts.

\section{Longitudinal section methodology}

The longitudinal section crypt method described by Wright $e t a l^{8}$ was used throughout the study. The total number of interphase and mitotic cell nuclei located in the left hand column of 30 well oriented crypts/mucosal biopsy specimen was counted, starting from the crypt base and ending at the crypt-villus junction. The criteria used for selecting suitable crypts included evidence of Paneth cells at the crypt base, as well as the crypts showing a 'defined' crypt-villus junction and evidence of a central lumen. 


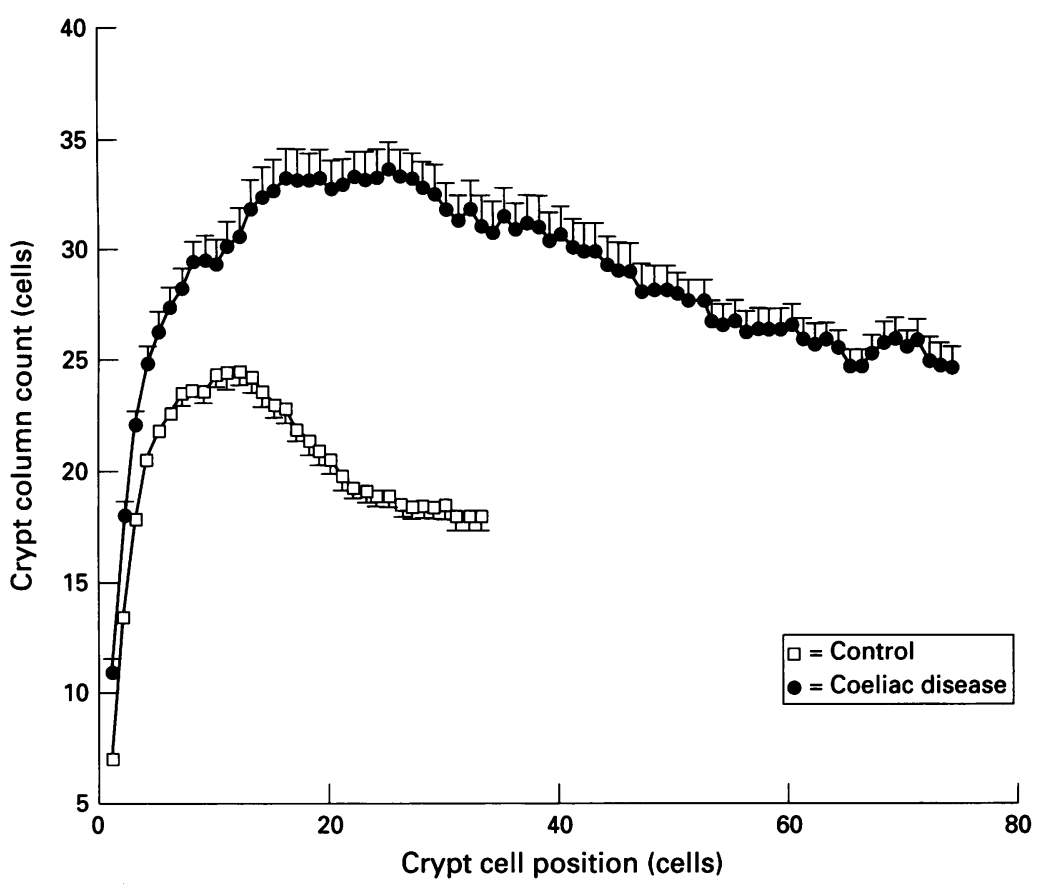

Figure 3: Crypt dimensions measured using confocal microscopy. Crypt width (column count) versus longitudinal cell position in control (127 crypts measured from 11 patients; median age 31 months) and in coeliac disease (69 crypts measured from six patients; median age 33 months). Error bars indicate mean (SEM).

\section{Crypt normalisation and statistics}

To take into account the variability in crypt size, ${ }^{20}$ these were normalised by representing the position of each mitosis as a percentage distance along the length of the crypt column. These values were subsequently extrapolated back onto a normalised crypt structure for control and coeliac disease, respectively. In the confocal microscopical studies, mitotic figures were also normalised to take into account the variation in crypt width, thereby fitting cell divisions onto a normalised column count for each longitudinal crypt cell position. All statistical analyses were calculated using the Welch test ${ }^{21}$ and were additionally corroborated using the Mann-Whitney U test for ranks, both of which are available on MINITAB Statistical Software (Minitab, State College, PA 16801, USA). The crypt growth

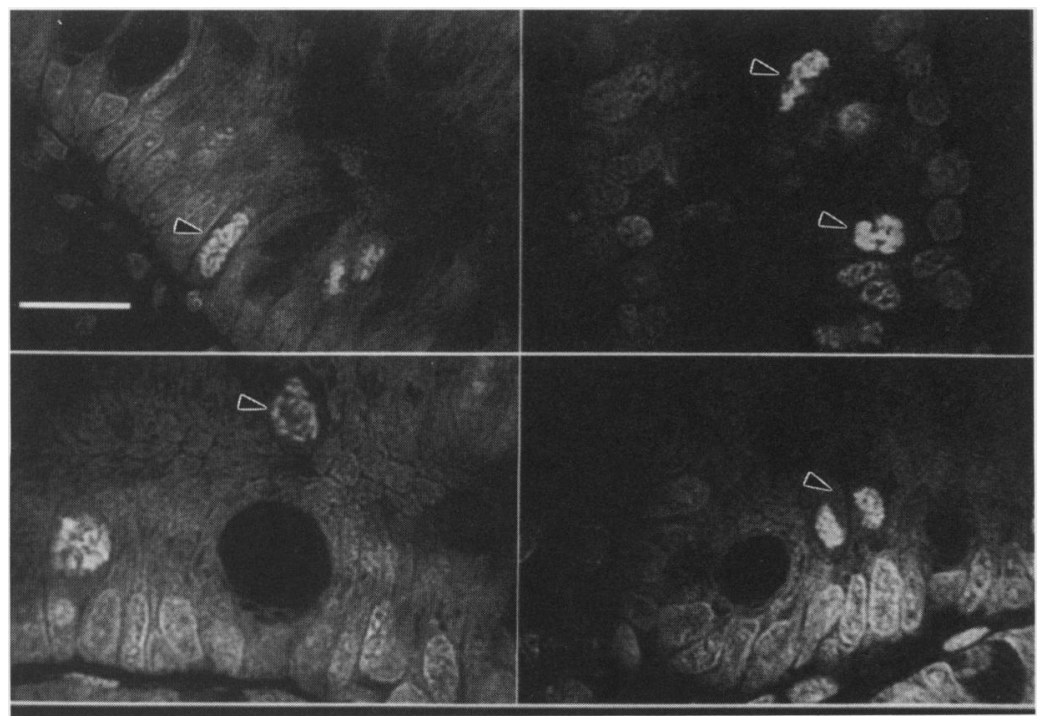

Figure 4: Fluorescently labelled epithelial cell nuclei (arrowheads) in prophase (upper left), metaphase (upper right), anaphase (lower left), and telophase (lower right) stages of mitosis (scale bar represents $10 \mu \mathrm{m}$ ). fraction $\left(I_{p}\right)$ was calculated as described previously. ${ }^{13}$ Briefly, a curve fitting option available on Genstat 5 was applied to 2-D longitudinal section and confocal microscopical mitotic index $\left(I_{m}\right)$ distribution curves to display peak $I_{m}$ values. Calculation and extrapolation of the 'half mid-way point' or $I_{m}$ $\max _{50 \%}$ to the $\mathrm{x}$ axis displayed the longitudinal crypt cell position defining the theoretical division between the crypt proliferation and maturation compartment. The growth fraction $\left(I_{p}\right)$ was subsequently calculated by expressing the proliferation compartment as a percentage of the total crypt cell population, representing the proportion of crypt cells that are actively cycling.

\section{Results}

\section{Histological features}

Analysis of $3 \mu \mathrm{m}$ thick paraffin wax sections stained either by the haematoxylin and eosin or periodic acid Schiff methods confirmed the characteristic histological findings of untreated coeliac disease (Fig 1). There was clear evidence of severe flat mucosa and hyperplastic crypts, the second structures often opening into a common vestibule. An abundance of mitoses was evident within the crypt epithelium and were often located in cell positions approaching the crypt-villus junction. The lamina propria possessed a heavy leucocytic infiltration. In addition, the surface epithelium displayed evidence of nuclear pseudostratification and a raised lymphocytic presence.

\section{Crypt morphology}

Confocal microscopical analysis of intact microdissected crypts stained with the fluorescent DNA binding probe propidium iodide, ${ }^{22}$ corroborated the histological findings by showing coeliac crypts to possess substantially more cells $(3 \cdot 8$-fold; $p<0.001)$ compared with histologically normal mucosa (Table; Figs 2 and 3). In coeliac disease, the crypt cell population calculated using mathematical summation of longitudinal section data correlated well with actual counts obtained using confocal microscopical data. Longitudinal section methodology, however, significantly overestimated the crypt cell population in histologically normal crypts (Table). Mathematical modelling required to calculate the total crypt cell population and crypt cell production rate (CCPR) using longitudinal section methods assume crypts to be cylindrical. ${ }^{13} 17$ Quantitative measurements of serial confocal images, however, showed crypts to be flask shaped, with most epithelial cells recorded in lower cell positions (Fig 3). On average, $20 \%$ and $33 \%$ more cells were recorded in the lower compared with the upper half of coeliac and control crypts, respectively.

Mitotic index $\left(I_{\mathrm{m}}\right)$ distribution curves

All stages of the mitotic cell cycle were readily identified by confocal imaging of fluorescently 


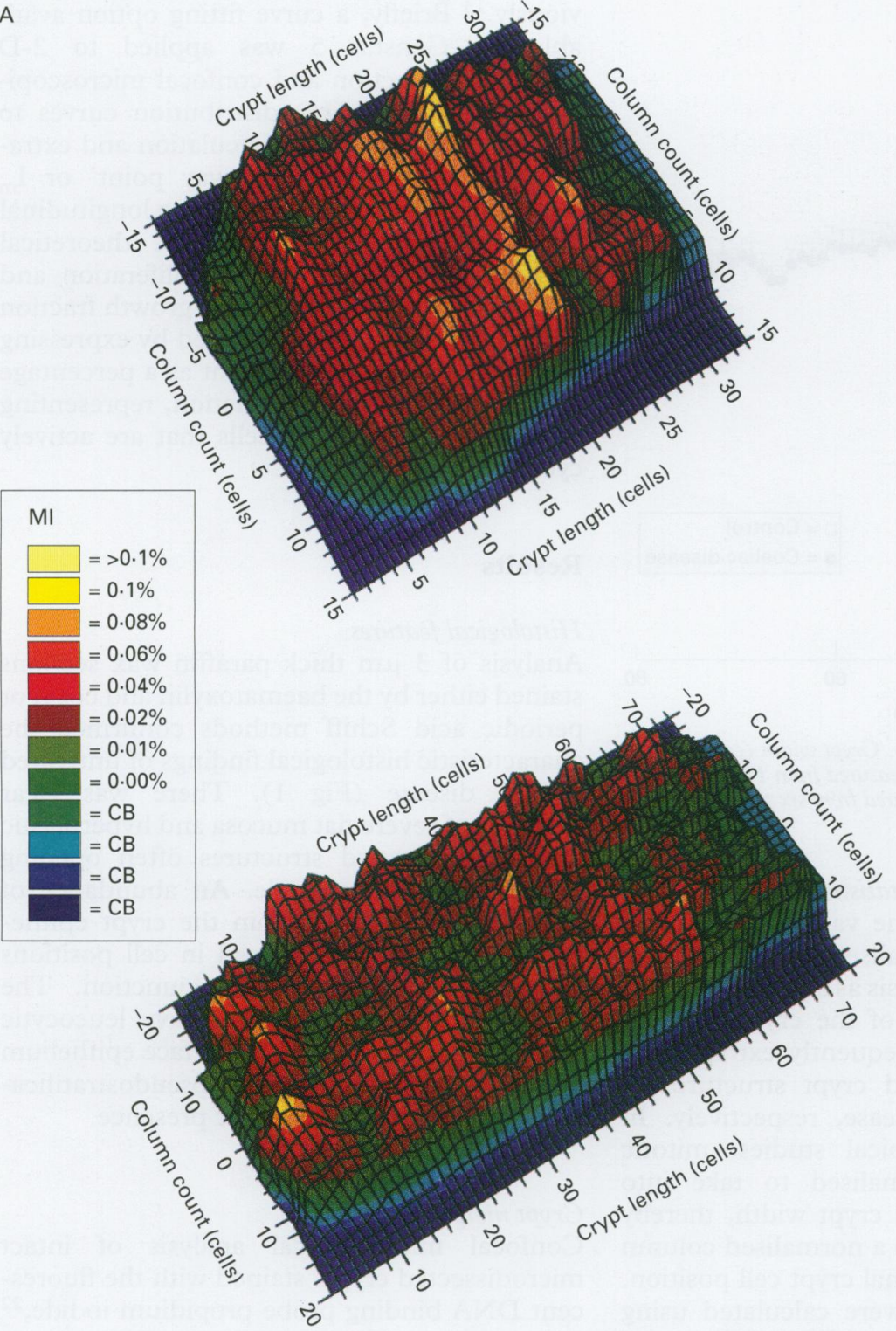

Figure 5: (A) 3-D $I_{\mathrm{m}}$ distribution curves were plotted to conform to average crypt dimensions (Fig 3). A total of 885 and 1356 mitotic figures were recorded from control (upper) and coeliac patients (lower), respectively. The position of individual mitotic figures has been normalised to fit into the average crypt boundaries, thereby overcoming the problem of crypt length and width variability affecting the $I_{\mathrm{m}}$ distribution curve. The colour thermals show the average $I_{\mathrm{m}}$ at individual cell positions ( $C B$, crypt boundary; $M I$, mitotic index $\left(I_{\mathrm{m}}\right)$. The $3-D$ graphs were created using Unimap computer software on a digital 4000 series micro-vax system. (B) $2-D I_{\mathrm{m}}$ distribution curves, created from 3-D confocal microscopical (CM) data, are compared with results obtained using longitudinal section (LS) methodology. Crypts have been normalised to compensate for variability in column lengths and the average $I_{\mathrm{m}}$ for each longitudinal cell position is illustrated. The crypt growth fraction $\left(I_{\mathrm{p}}\right)$ or proliferation compartment represents the crypt cell population to the left of the half mid-way point (broken line), calculated from a knowledge of the I max 5 . The growth fraction represents $70 \%$ and $82 \%$ of cells for control crypts; $60 \%$ and $84 \%$ of cells for coeliac crypts using longitudinal section and confocal microscopical methods, respectively (Table). Data from control patients are shown in the two left hand panels and data from coeliac patients in the two right hand panels.

labelled epithelial cell nuclei (Fig 4). A characteristic feature noted using confocal microscopy was that dividing cells migrated centripetally towards the crypt lumen during the mitotic cycle, as has been described previously. ${ }^{17}$ The most centripetally positioned mitotic figures appeared in anaphase, where in most cases the mitotic spindle lined up parallel to the longitudinal crypt axis. Confocal microscopy was used to map individual mitotic figures in control and coeliac crypts, respectively, thereby permitting accurate $3-\mathrm{D} \mathrm{I}_{\mathrm{m}}$ distribution curves (Fig 5) to be calculated (885 mitoses from 127 crypts were measured from 11 control patients and 1356 mitoses from 69 crypts were measured from six patients with coeliac disease). It is clear from these curves that the mitotic activity is distributed fairly evenly throughout both types of crypts, with evidence of a rapid drop in mitotic activity in regions approaching the crypt base and
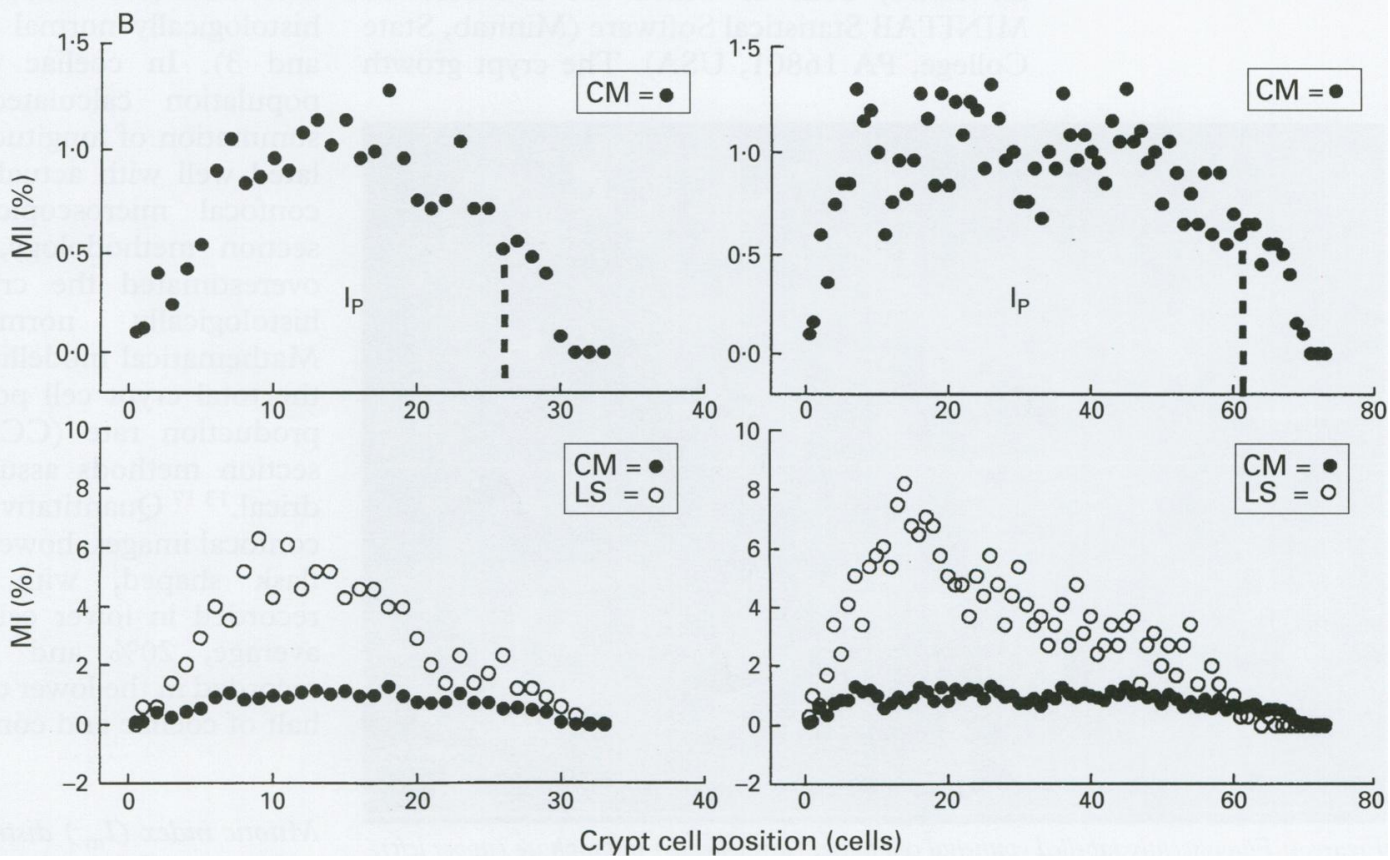

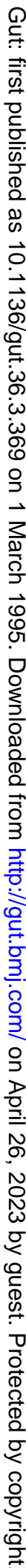

Crypt cell position (cells) 
crypt-villus junction. This is shown further in the 2-D $I_{m}$ distribution curves created from confocal microscopical and longitudinal section data, respectively, showing large discrepancies between the two different methods (Fig 5). The longitudinal section method greatly overestimates the $I_{m}$, especially in lower crypt cell positions. Calculation of the size of the crypt proliferation and maturation compartments, from a knowledge of the $I_{m}$ $\max _{50}$ for the respective curves (Fig 6), showed no significant change in the comparative size of the growth fraction $\left(I_{p}\right)$ in either group (Table).

CCPR and 'corrected' crypt $I_{\mathrm{m}}$

Values for CCPR assume the mitotic duration to be about one hour and to remain constant in coeliac disease. ${ }^{23}$ Confocal microscopical values obtained for CCPR in control and coeliac disease are in good agreement with previously published crypt squash data, ${ }^{24} 25$ but are significantly lower than those calculated using longitudinal sections (Table). As the confocal microscopical technique may be used to show the actual crypt growth fraction $\left(I_{p}\right)$, as defined by the $I_{m}$ distribution curves, this permits a calculation of a 'corrected' crypt $I_{m}\left(\%\right.$ of $\left.I_{p}\right)$. As is seen for CCPR, large discrepancies were also shown when calculating the 'corrected' crypt $I_{m}$ using confocal microscopical and longitudinal section methods, respectively (Table). Confocal microscopy showed no significant measurable difference in $I_{m}$ between control and coeliac crypts mean (SEM) $(1.01(0.04) \%$ and 1.13 $(0.07) \%$ for control and coeliac disease, respectively; $\mathrm{p}>0.05$ ). A statistical difference was shown, however, when calculating the $I_{m}$ using longitudinal section methodology $(2 \cdot 97$ $(0.22) \%$ and $4.21 \quad(0.41) \%$ for control and coeliac disease, respectively; $\mathrm{p}<0 \cdot 001)$.

\section{Discussion}

This study has described a novel technique using confocal microscopy to provide detailed quantitative measurements of small intestinal proliferration in children. Specifically, the investigation has critically re-examined the previously well accepted adaptive proliferative responses that have been reported to occur during gastrointestinal damage, for example, in coeliac disease. ${ }^{581823-26}$ By fluorescently labelling both dividing and non-dividing epithelial cell nuclei in intact microdissected crypts, confocal microscopy has provided accurate quantitative data that relates to the distribution of mitosis in control and coeliac crypts. This has provided new information that affects previous concepts regarding adaptive change in the crypt size, growth fraction, $\mathrm{I}_{\mathrm{m}}$, and cell cycle times, all of which influence CCPR. ${ }^{12} 13$

The confocal microscopical data reconfirmed previous reports describing an intestinal hyperproliferative response in coeliac disease. ${ }^{581823-26}$ From a knowledge of the absolute number of mitoses per crypt, CCPR was shown to be $3 \cdot 9$-fold higher in coeliac compared with histologically normal patients (Table). In this respect, confocal microscopy closely agrees with previous Feulgen stained crypt squash values for CCPR in control and coeliac human small mucosa. These CCPR values were consistently three to fourfold lower than estimates calculated using longitudinal section methodology. Thus, Tannock's correction factor needs to be reduced from 0.7 to 0.27 to consistently produce results that are comparable with those obtained using confocal microscopy.

The Feulgen crypt squash method, although able to provide accurate measures for CCPR, is unable to provide information detailing the precise adaptive responses that increase CCPR in coeliac disease. This includes information relating to the measurement of changed proliferation and maturation compartments, as well as a value for the corrected crypt $I_{m}$. All of these kinetic parameters rely on an accurate calculation of the crypt growth fraction. The confocal microscopical technique can provide these data and, as such, is advantageous over the crypt squash technique. In addition, the ability of this method to optically focus through intact tissues eliminates the problem of having to identify individual mitoses in crypts where there is an extensive infiltrating leucocyte population or epithelial cell loss and debris within the lumen of these structures.

The confocal microscopical 3-D $\mathrm{I}_{\mathrm{m}}$ distribution curves permitted an average $I_{m}$ to calculate for each cell position within normalised control and coeliac crypts. These 3-D data were subsequently used to calculate the respective crypt growth fractions. In contrast with previous publications, $8182326 \mathrm{I}_{\mathrm{p}}$ was shown to represent over $80 \%$ of the crypt and to remain constant in coeliac disease (Table). From a knowledge of these growth fractions, a corrected crypt $\mathrm{I}_{\mathrm{m}}$ was calculated for each group. No significant difference in the crypt $I_{m}$ was shown in coeliac disease compared with histologically normal mucosa (Table), which was surprising as this value has been reported to double in coeliac disease. ${ }^{8182326}$ Two important reasons contribute towards these discrepancies. Firstly, the uneven abundance of epithelial cells recorded along the crypt length, as shown by confocal microscopy, effectively reduces the $I_{m}$ in the lower crypt region. Secondly, the flask shaped nature of the crypts makes correction factors (for example, Tannock's factor) highly inaccurate as these are dependant upon constant radial distances within the crypt. Consideration of crypt architecture, therefore, profoundly changes the shape of $I_{m}$ distribution curves and, consequently, influences the concept of entirely separate proliferation and maturation compartments within the crypt, as these are defined mathematically from the $I_{m}$ distribution curves. Thus, confocal microscopy showed the growth fraction in human small intestinal crypts to be larger than initially conceived, this being particularly apparent in coeliac disease.

In summary, confocal microscopy showed serious discrepancies when applying Tannock's correction factor to calculate intestinal 
proliferation using longitudinal sections. Consequently, values for CCPR have been greatly overestimated in the past. These discrepancies introduced large errors when calculating the crypt $I_{m}$ and growth fractions, as mitotic activity was shown by confocal microscopy to be fairly uniform throughout most of the crypt. These results now show that, rather than a reduction in cell cycle time or a change in the crypt growth fraction, the main adaptive mechanism influencing CCPR in coeliac disease is the size of the crypt population. Attention should, therefore, be focused on elucidating factors that regulate this parameter to better understand the intestinal hyperproliferative response. As a consequence, it is now particularly important to extend confocal microscopical studies to intestinal cancer in an attempt to establish whether a similar phenomenon exists in such conditions, caused as a result of neoplastic change in the crypt architecture.

This work was supported by the Queen Elizabeth Hospital for Children Research Appeal Trust. The authors thank Dr Doug Children Research Appeal Trust. The authors thank Dr Doug
Winton, Dr David Brown, Dr Andrej Shmakov, and Professor Michael Smith for their helpful comments.

1 Lipkin M, Blattner MW, Gardner EJ, Burt RW, Lynch H, Deschner E. Classification and risk assessment of individuals with familial polyposis Gardner's syndrome, and familial non-polyposis colon cancer from [ $\left.{ }^{3} \mathrm{H}\right]$ thymidine labelling patterns in colonic epithelial cells. Cancer Res 1983; 44: 1899-904.

2 Romagnoli P, Filipponi F, Bandettini L, Brugnola D. Increase in mitotic activity in the colonic mucosa of patients Increase in mitotic activity in the colonic mucosa of patients
with colorectal cancer. Dis Colon Rectum 1984; 27: 305-8. 3 Bleiberg H, Buyse M, Galand P. Cell kinetic indicators of premalignant stages of colorectal cancer. Cancer 1985; 56: 124-9.

4 Potten CS, Kellett M, Rew DA, Roberts SA. Proliferation in human gastrointestinal epithelium using bromodeoxyuridine in vivo: data for different sites, proximity to a tumour and polyposis coli. Gut 1992; 33: 524-9.

5 Trier JS, Browning TD. Epithelial-cell renewal in cultured duodenal biopsies in coeliac disease. N Engl f Med 1970; 283: 1245-50.

6 Walker-Smith JA, Phillips AD, Walford N, Gregory H, Fitzgerald JD, MacCullagh $\mathrm{K}$, et al. Intravenous epider-
mal growth factor/urogastrone increases small intestinal mal growth factor/urogastrone increases small intestinal cell proliferation in

7 Dowling RH, Gleeson MH. Cell turn-over following small bowel resection and by-pass. Digestion 1973; 8: 176-90.
8 Wright N, Watson A, Morley A, Appleton D, Marks J. Cell kinetics in flat (avillous) mucosa of the human small intestine. Gut 1973; 14: 701-10.

9 Cheng H, Leblond CP. Origin, differentiation and renewal of the four main epithelial cell types in the mouse small intestine. Am ₹ Anat 1974; 141: 537-63.

$10 \mathrm{Hauft} S M$, Kim SH, Schmidt GH, Pease $S$, Rees $S$, Harris $\mathrm{S}$, et al. Expression of SV-40 T antigen in the small intestinal epithelium of transgenic mice results in proliferintestinal epithelium of transgenic mice results in prolifer-
ative changes in the crypt and reentry of villus-associated ative changes in the crypt and reentry of villus-associated
enterocytes into the cell cycle but has no apparent effect on cellular differentiation programs and does not cause neoplastic transformation. $\mathcal{F}$ Cell Biol 1992; 117: 825-39.

11 Winton DJ, Ponder BAJ. Stem-cell organization in mouse small intestine. Proc $R$ Soc Lond 1990; 241: 13-8.

12 Appleton DR, Sunter JP, Watson AJ. Cell proliferation in the gastrointestinal tract. Bath: Pitman Press, 1980.

13 Wright NA, Alison MR. The biology of epithelial cell populations (Vols I and II). Oxford: Clarendon Press, 1984.

14 Potten CS, Loeffler M. Stem cells: attributes, cycles, spirals, pitfalls and uncertainties. Lessons for and from the crypt. Development 1990; 110: 1001-20.

15 Goodlad RA, Levi S, Lee CY, Mandir N, Hodgson H, Wright NA. Morphometry and cell proliferation in endoscopic biopsies: evaluation of a technique. Gastroenterology 1991; 101: 1235-41.

16 Potten CS, Roberts SA, Chwalinski S, Loeffler M, Paulus U. Scoring mitotic activity in longitudinal sections of crypts of the small intestine. Cell Tissue Kinet 1988; 21: 231-46.

17 Tannock IF. A comparison of the relative efficiencies of various metaphase arrest agents. Exp Cell Res 1967; 47: 345-56.

18 Watson AJ, Appleton DR, Wright NA. Adaptive cell-proliferative changes in the small intestinal mucosa in coeliac liferative changes in the small intestinal mucosa
disease. Scand $f$ Gastroenterol 1982; 17: 115-27.

19 Walker-Smith JA, Guandalini S, Schmitz J, Shmerling DH, Visakorpi JK. Revised criteria for diagnosis of coeliac disease. Report of working group of ESPGAN. Arch Dis Child 1990; 65: 909-11.

20 Totafurno J, Bjerkes $M$, Cheng $H$. Variation in crypt size and its influence on the analysis of epithelial cell proliferation in the intestinal crypt Biophys 7 1988; 54: 845-58.

21 Welch BL. The significance of the difference between two means when the population variances are unequal. means when the populatio
Biometrika 1937; 29: 350-62.

22 Merdes A, Stelzer EHK, De Mey J. The three-dimensional architecture of the mitotic spindle, analyzed by confocal fluorescence and electron microscopy. $\mathscr{f}$ Electron Microsc Tech 1991; 18: 61-73.

23 Wright N, Watson A, Morley A, Appleton D, Marks J, Douglas A. The cell cycle time in the flat (avillous) mucosa of the human small intestine. Gut 1973; 14: 603-6.

24 Ferguson A, Sutherland A, MacDonald TT, Allan F. Technique for micro-dissection and measurement in biopsies of human small intestine. $\mathcal{F}$ Clin Pathol 1977; 30: 1068-73.

25 Challacombe DN, Wheeler EE. The use of a stathmokinetic technique with crypt microdissection to estimate the crypt cell production rate in cultured explants of the duodenal cell production rate in cultured explants of the duodenal
mucosa in celiac disease. Hepatogastroenterology 1992; 39: mucosa

26 Kosnai I, Kuitunen P, Savilahti E, Rapola J, Kohegyi J. Cell kinetics in the jejunal crypt epithelium in malabsorption syndrome with cow's milk protein intolerance and in coeliac disease of childhood. Gut 1980; 21: 1041-6. 